\title{
PEMAHAMAN INFORMASI LAYANAN JAMINAN KESEHATAN DENGAN MOTIVASI MENAMBAL GIGI PASIEN POLIKLINIK ENDODONSI RSUD BUDHI ASIH TAHUN 2019-2020
}

\author{
Sesma Apriella ${ }^{1}$, Emma Kamelia ${ }^{2}$, Rieza Zulfahmi $\mathbf{T}^{3}$ \\ ${ }^{1,2,3}$ Program Studi Terapi Gigi Jurusan Keperawatan Gigi Poltekkes Kemenkes Tasikmalaya, Indonesia
}

\begin{tabular}{|c|c|}
\hline Info Artikel & Abstrak \\
\hline Genesis Naskah: & \multirow{9}{*}{$\begin{array}{l}\text { Latar Belakang: Informasi memiliki dampak terhadap pengetahuan, motivasi serta sebagai bahan dalam } \\
\text { membuat keputusan bagi kesehatan masyarakat luas. Pemerintah membentuk pusat layanan untuk memenuhi } \\
\text { kebutuhan masyarakat dibidang kesehatan seperti Rumah Sakit dan Puskesmas dan memfasilitasi dengan } \\
\text { Jaminan Sosial Kesehatan. Mayoritas pasien poliklinik endodonsi RSUD Budhi Asih berobat karena sakit } \\
\text { atau bengkak dengan status kunjungan melalui pendaftaran pasien umum. Tujuan: Menganalisis hubungan } \\
\text { pemahaman informasi layanan jaminan kesehatan dengan motivasi menambal gigi pasien poliklinik } \\
\text { endodonsi RSUD Budhi Asih tahun } 2019-2010 \text {. Metode: Penelitian survey dengan pendekatan cross } \\
\text { sectional, Sampel penelitian } 256 \text { responden, diambil dengan teknik simple random sampling. Alat ukur } \\
\text { menggunakan lembar ceklis sebanyak } 9 \text { pertanyaan tentang informasi layanan jaminan kesehatan yang telah } \\
\text { di uji validitas dan reliabilitas,serta format pemeriksaaan performed treatment index (PTI) untuk melihat } \\
\text { tingkat motivasi menambal gigi pasien. Hasil: Deskrpsi kriteria pemahaman informasi layanan jaminan } \\
\text { kesehatan kriteria baik memiliki persentase motivasi menambal gigi baik } 87 \% \text { dan kriteria buruk 13\%, } \\
\text { kriteria pemahaman informasi layanan jaminan kesehatan kurang memiliki pesentase motivasi menambal } \\
\text { gigi baik } 92 \% \text { dan kriteria buruk } 8 \% \text { Kesimpulan: Pasien yang memiliki informasi layanan jaminan } \\
\text { kesehatan kurang memiliki motivasi menambal gigi baik setelah mendapatkan informasi tentang layanan } \\
\text { jaminan kesehatan dari tenaga kesehatan. }\end{array}$} \\
\hline Submitted: 2021-02-25 & \\
\hline Revised: 2021-08-15 & \\
\hline Accepted: 2021-08-27 & \\
\hline Kata Kunci: & \\
\hline Informasi layanan jaminan & \\
\hline kesehatan, Motivasi & \\
\hline Menambal Gigi, Pasien & \\
\hline Poliklinik Endodonsi & \\
\hline
\end{tabular}

\section{UNDERSTANDING OF HEALTH ASSURANCE SERVICE INFORMATION WITH THE MOTIVATION OF DENTAL FILLINGS ENDODONY POLYCLINIC PATIENTS BUDHI ASIH HOSPITAL IN 2019-2020}

\section{Keywords:}

Information on health

insurance services, Teeth

Filling Motivation,

Endodontic Patients

\begin{abstract}
Background: Information has an impact on knowledge, motivation and as an ingredient in making decisions for public health. The government establishes service centers to meet the needs of the community in the health sector such as hospitals and health centers and facilitates with Health Social Security. The majority of endodontic polyclinic patients at Budhi Asih Hospital were treated for pain or swelling with visit status through general patient registration. Objective: To analyze the relationship between understanding information on health insurance services and the motivation for filling the teeth of patients at the endodontic polyclinic of Budhi Asih Hospital in 2019-2010. Methods: Survey research with a cross sectional approach. The research sample was 256 respondents, taken by using simple random sampling technique. The measuring instrument uses a checklist consisting of 9 questions regarding information on health insurance services that have been tested for validity and reliability, as well as the format for examining the performed treatment index (PTI) to see the level of motivation for filling the patient's teeth. Results: The description of the criteria for understanding information on health insurance services with good criteria has a good percentage of $87 \%$ motivation for filling teeth and $13 \%$ for bad criteria, the criteria for understanding information on health insurance services lacks a percentage of motivation for filling teeth with good 92\% and bad criteria 8\% Conclusion: Patients who have Information on health insurance services lacks motivation for filling teeth after getting information about health insurance services from health workers.
\end{abstract}

\section{Korespondensi Penulis:}

Sesma Apriella

Email: sesmapriella04@gmail.com 


\section{Pendahuluan}

Kesehatan merupakan hak asasi manusia dan salah satu unsur kesejahteraan yang harus diwujudkan (Kemenkes, 2009). Pembangunan kesehatan sebagai salah satu unsur kesejahteraan umum maka ditujukan untuk meningkatkan kesadaran, kemauan dan kemampuan hidup sehat bagi setiap orang dalam rangka mewujudkan derajat kesehatan yang optimal (Depkes, 2014). Setiap orang mempunyai hak yang sama memperoleh derajat kesehatan yang optimal. Setiap orang berkewajiban untuk ikut serta dalam memelihara dan meningkatkan derajat kesehatan perseorangan, keluarga, dan lingkungannya (Kemenkes, 2009). Kesehatan rongga mulut merupakan bagian integral dari kesehatan secara umum. Rongga mulut yang sehat memungkinkan seseorang untuk berkomunikasi secara efektif, menikmati berbagai macam makanan, meningkatkan kualitas hidup, percaya diri dan mempunyai kehidupan sosial yang lebih baik (Barahama, Masi, \& Hutauruk, 2018). Keadaan tersebut dapat dilakukan melalui edukasi yang di dalamnya berisi pemberian informasi (Astuti, Nurmalita, \& Doni, 2014).

Informasi dapat diberikan melalui media elektronik, media cetak, petugas kesehatan, kader dan keluarga (Depkes, 2014). Petugas kesehatan memberikan informasi-informasi yang berkaitan dengan kebutuhan masyarakat untuk mencapai derajat kesehatan yang optimal, dimana saat ini pemerintah memfasilitasi melalui sistem jaminan social (Depkes, 2014; Kemenkes, 2011).

Negara mengembangkan sistem jaminan sosial nasional bagi seluruh rakyat Indonesia untuk memberikan jaminan sosial yang menyeluruh. Sistem Kesehatan Nasional (SKN) menjelaskan bahwa upaya yang dilakukan dalam mewujudkan derajat kesehatan maka sangat dibutuhkan dukungan oleh perbaikan sumber daya yang optimal berupa upaya kesehatan, pembiayaan kesehatan, sumber daya manusia kesehatan, pemberdayaan masyarakat, sediaan farmasi, alat kesehatan dan makanan serta manajemen dan informasi kesehatan (Kemenkes, 2011). Informasi merupakan salah satu motivasi yang berasal dari luar individu (Lendrawati, 2013; Rizqi, 2016).

Setiap orang berhak atas jaminan sosial untuk dapat memenuhi kebutuhan dasar hidup yang layak dan meningkatkan martabatnya menuju terwujudnya masyarakat Indonesia yang sejahtera, adil, dan makmur maka negara memberikan jaminan sosial yang menyeluruh. Badan hukum yang dibentuk untuk menyelenggarakan program Jaminan

(C) Jurusan Keperawatan Gigi Poltekkes Kemenkes Jakarta I J1. Wijaya Kusuma No. 47-48 Cilandak Jakarta Selatan, Indonesia email: jdht@poltekkesjakarta1.ac.id
Kesehatan adalah badan Penyelenggara Jaminan Sosial Kesehatan yang disingkat BPJS Kesehatan. Jenis layanan kesehatan yang diselenggarakan oleh BPJS Kesehatan perlu dipahami karena terdapat kategori-kategori layanan yang tidak diansuransikan oleh BPJS. Pemahaman di masyarakat mempengaruhi pola hidup dalam kelompok masyarakat dan mempengaruhi tingkat kesehatan di masyarakat (Depkes, 2013).

Prevalensi masalah gigi dan mulut di Indonesia masih sangat besar. Berdasarkan Riset Kesehatan Dasar (Riskesdas) 2018, sebanyak 57,6 persen orang Indonesia memiliki masalah gigi dan mulut dengan 21 provinsi mempunyai prevalensi masalah gigi dan mulut di atas angka nasional. Angka persentase penduduk yang memiliki masalah kesehatan gigi dan mulut dalam 12 bulan yang dikalikan dengan persentase penduduk menerima perawatan atau pengobatan dari tenaga medis gigi (EMD) sebesar 10,2\%. Masalah kesehatan gigi dan mulut di Provinsi DKI Jakarta diatas angka nasional (Kemenkes, 2018).

Informasi memiliki dampak yang sangat berpengaruh terhadap kesehatan masyarakat (Astuti et al., 2014). Informasi menggambarkan kondisi objektif masalah untuk mengambil keputusan yang tepat sesuai dengan gambaran kejadian yang diberikan informasi (Setiawan, 2020). Pengetahuan tentang penyakit gigi penting untuk mengetahui cara memelihara kesehatan gigi untu meingkatkan motivasi mempertahankan gigi. Pengetahuan yang didapat seseorang akan membentuk sikap yang merupakan predisposisi untuk perilaku mempertahankan gigi (Lendrawati, 2013).

Berdasarkan penelitian yang dilakukan sebelumnya oleh Pangestu, 2018 pada peserta BPJS di Dusun Ulo Jember terdapat hubungan antara tingkat pengetahuan peserta BPJS kesehatan tentang BPJS pada bidang kesehatan gigi dan mulut dengan pemanfaatan fasilitas BPJS oleh peserta BPJS (Pangestu, 2018). Hasil survey awal diperoleh data pada 1 tahun terakhir di Poliklinik Endodonsi RSUD Budhi Asih pasien yang datang berobat ke poliklinik endodonsi adalah pasien yang terpaksa berobat karena sakit yang tidak tertahankan atau bengkak yang sudah besar dengan status pendaftaran sebagai pasien umum. Mayoritas pasien kunjungan pertama melakukan pendaftaran dengan status pendaftaran umum dan beberapa pasien kunjungan kedua atau selanjutnya dengan status pendaftaran BPJS. Pasien BPJS yang berobat selalu diberi jadwal kontrol dan

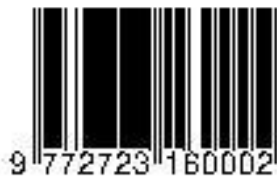


pasien selalu datang tepat pada waktu yang telah dijadwalkan (SIMRS, 2020). Berdasarkan uraian diatas peneliti ingin mengetahui hubungan pemahaman informasi layanan jaminan kesehatan dengan motivasi menambal gigi pasien poliklinik endodonsi RSUD Budhi Asih.

\section{Metode}

Jenis penelitian menggunakan metode survey yang bersifat analitik. Penelitian menggunakan desain penelitian cross sectional yaitu penelitian yang digunakan untuk mempelajari dinamika korelasi dengan cara mengidentifikasi tingkat pemahaman informasi layanan jaminan kesehatan pasien menggunakan lembar ceklis kemudian ditelusuri tentang motivasi menambal gigi pasien dengan melihat data menambal gigi pasien setelah 2 bulan dari kedatangan pertama pada rekam medis pasien poliklinik endodonsi RSUD Budhi Asih Tahun 2019-2020. Populasi dalam penelitian ini adalah seluruh pasien poliklinik edodonsi RSUD Budhi Asih tahun 20192020 yang berjumlah 705 pasien. Jumlah sampel pada penelitian ini adalah 256 pasien, penentuan sampel dilakukan dengan teknik simple random sampling dengan menggunakan rumus slovin. Alat ukur dalam penelitian ini menggunakan lembar ceklis pertanyaan yang dibuat oleh peneliti yang telah di uji validitas reliabilitas dan format pemeriksaaan Performed treatment index (PTI) untuk melihat tingkat motivasi menambal gigi pasien.

\section{Hasil}

Penelitian dilaksanakan di Poliklinik Endodonsi RSUD Budhi Asih. Hasil penelitian diperoleh data sebagai berikut:

Tabel 1. Distribusi Frekuensi Pasien Poliklinik Endodonsi berdasarkan Jenis Kelamin

\begin{tabular}{lcc}
\hline Jenis kelamin & $\begin{array}{c}\text { Frekuensi } \\
(\mathrm{f})\end{array}$ & Persentase (\%) \\
\hline Laki-laki & 98 & 38 \\
Perempuan & 158 & 62 \\
\hline Jumlah & 256 & 100 \\
\hline
\end{tabular}

Berdasarkan tabel 1 diatas terlihat bahwa jenis kelamin yang paling banyak adalah perempuan sebanyak $62 \%$.

(C) Jurusan Keperawatan Gigi Poltekkes Kemenkes Jakarta I Jl. Wijaya Kusuma No. 47-48 Cilandak Jakarta Selatan, Indonesia email: jdht@poltekkesjakarta1.ac.id
Tabel 2. Distribusi Frekuensi pemahaman informasi layanan jaminan kesehatan

\begin{tabular}{lcc}
\hline $\begin{array}{c}\text { Pemahaman } \\
\text { informasi } \\
\text { Layanan } \\
\text { Jaminan } \\
\text { Kesehatan }\end{array}$ & Frekuensi (f) & Persentase (\%) \\
\hline $\begin{array}{l}\text { Baik } \\
(76 \%-100 \%)\end{array}$ & 15 & 6 \\
$\begin{array}{l}\text { Sedang } \\
(56 \%-75 \%)\end{array}$ & 55 & 21 \\
$\begin{array}{l}\text { Kurang } \\
(<56 \%)\end{array}$ & 186 & 73 \\
\hline Jumlah & 256 & 100 \\
\hline
\end{tabular}

Berdasarkan tabel 2 di atas terlihat dari 256 pasien sebanyak 186 pasien (73\%) menjawab kuesioner mengenai informasi layanan jaminan kesehatan dengan kriteria kurang dan yang menjawab kuesioner mengenai informasi layanan jaminan kesehatan dengan kriteria baik hanya 15 pasien $(6 \%)$.

Tabel 3. Distribusi Frekuensi Motivasi Menambal Gigi

\begin{tabular}{ccc}
\hline PTI & Frekuensi (f) & $\begin{array}{c}\text { Persentase } \\
(\%)\end{array}$ \\
\hline Baik $(\geq 20 \%)$ & 228 & 89 \\
Buruk $(<20 \%)$ & 28 & 11 \\
\hline Jumlah & 256 & 100 \\
\hline
\end{tabular}

Berdasarkan tabel 3 di atas terlihat dari 256 pasien sebanyak 228 pasien (89\%) memiliki kriteria motivasi menambal gigi baik dan kriteria menambal gigi buruk hanya 28 pasien (11\%).

Tabel 4. Hubungan Pemahaman Informasi Layanan Jaminan Kesehatan dengan Motivasi Menambal Gigi

\begin{tabular}{|c|c|c|c|c|c|c|}
\hline \multirow{3}{*}{$\begin{array}{l}\text { Informasi } \\
\text { Layanan } \\
\text { Jaminan } \\
\text { Kesehatan }\end{array}$} & \multicolumn{4}{|c|}{$\begin{array}{c}\text { Kriteria Motivasi } \\
\text { Menambal Gigi } \\
\text { (PTI) }\end{array}$} & Jumlah & \multirow[t]{3}{*}{$\%$} \\
\hline & \multicolumn{2}{|c|}{ Baik } & \multicolumn{2}{|c|}{ Buruk } & & \\
\hline & $\mathrm{F}$ & $\%$ & $\mathrm{~F}$ & $\%$ & & \\
\hline $\begin{array}{l}\text { Baik } \\
(76 \%-100 \%)\end{array}$ & 13 & 87 & 2 & 13 & 15 & 6 \\
\hline $\begin{array}{l}\text { Sedang } \\
(56 \%-75 \%)\end{array}$ & 44 & 80 & 11 & 20 & 55 & 21 \\
\hline $\begin{array}{l}\text { Kurang } \\
(<56 \%)\end{array}$ & 171 & 92 & 15 & 8 & 186 & 73 \\
\hline Jumlah & 228 & & 28 & & 256 & 100 \\
\hline
\end{tabular}

Berdasarkan tabel 4 diatas dapat dilihat bahwa pasien dengan kriteria informasi layanan jaminan

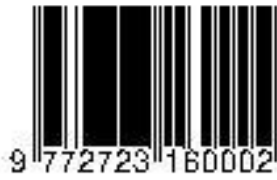


kesehatan baik memiliki persentase motivasi menambal gigi baik sebesar $87 \%$ dan memiliki motivasi menambal gigi buruk sebesar 13\% sedangkan kriteria pada informasi layanan jaminan kesehatan kurang memiliki persentasi motivasi menambal gigi baik $92 \%$ dan masih ada terdapat motivasi menambal gigi dengan kriteria buruk sebanyak $8 \%$.

Tabel 5. Uji Statistik Hubungan Pemahaman Informasi Layanan Jaminan Kesehatan Dengan Motivasi Menambal Gigi Chi-Square Tests

\begin{tabular}{|c|c|c|c|}
\hline & Value & Df & $\begin{array}{c}\text { Asymp. } \\
\text { Sig. (2-sided) }\end{array}$ \\
\hline $\begin{array}{l}\text { Pearson } \\
\text { Chi-Square }\end{array}$ & $6.302^{\mathrm{a}}$ & 2 & .043 \\
\hline
\end{tabular}

Berdasarlan tabel 5 diperoleh nilai p "value" sebesar 0,04 yang nilai signifikan tersebut kecil dari nilai 0,05 (p "value" $<0,05$ )

Tabel 6. Uji Statistik Koefisien Kontingensi Hubungan Pemahaman Informasi Layanan Jaminan Kesehatan Dengan Motivasi Menambal Gigi

Symmetric Measures

\begin{tabular}{llrc}
\hline & Value & $\begin{array}{c}\text { Approx. } \\
\text { Sig. }\end{array}$ \\
\hline $\begin{array}{l}\text { Nominal by } \\
\text { Nominal }\end{array}$ & $\begin{array}{l}\text { Contingency } \\
\text { Coefficient }\end{array}$ & .155 & .043 \\
\hline
\end{tabular}

Dari tabel 6 diatas dapat diketahui nilai kontingensi adalah 0,155 dengan koefisien korelasi sangat rendah antara informasi layanan jaminan kesehatan dengan motivasi menambal gigi pasien poliklinik endodonsi RSUD Budhi Asih.

\section{Pembahasan}

1. Pemahaman informasi layanan jaminan kesehatan pasien poliklinik endodonsi RSUD Budhi Asih.

Pemahaman informasi layanan jaminan kesehatan 256 responden sangat beragam, mulai dari kriteria baik, sedang, hingga kriteria kurang. Berdasarkan wawancara dari 256 reponden 15 (6\%) responden memiliki informasi layanan jaminan kesehatan dengan kriteria baik, 55 (21\%) responden memiliki informasi layanan jaminan kesehatan dengan kriteria sedang dan $186(73 \%)$ responden memiliki informasi

(C) Jurusan Keperawatan Gigi Poltekkes Kemenkes Jakarta I Jl. Wijaya Kusuma No. 47-48 Cilandak Jakarta Selatan, Indonesia email: jdht@poltekkesjakarta1.ac.id layanan jaminan kesehatan dengan kriteria kurang. Berdasarkan wawancara mengenai informasi layanan jaminan kesehatan yang dilakukan beberapa responden memiliki alasan tertentu dengan informasi layanan jaminan kesehatan yang mereka peroleh. Informasi layanan jaminan kesehatan yang sangat minimal diperoleh masyarakat menimbulkan pemikiran bahwa layanan jaminan kesehatan hanya bisa digunakan untuk keperluan mendadak, parah dan darurat.

Informasi layanan jaminan kesehatan dapat diberikan melalui media elektronik, media cetak, petugas kesehatan, kader dan keluarga (Depkes, 2014). Dalam melaksanakan fungsinya, beberapa tugas dan kewajiban BPJS untuk membayarkan manfaat dan/atau membiayai pelayanan kesehatan sesuai dengan ketentuan program jaminan sosial dan memberikan informasi mengenai penyelenggaraan program jaminan sosial kepada peserta dan masyarakat, memberikan manfaat kepada seluruh peserta sesuai dengan undang-undang tentang sistem jaminan sosial nasional (Kemenkes, 2011).

2. Motivasi Menambal Gigi Pasien Poliklinik endodonsi RSUD Budhi Asih tahun 2019-2020.

Berdasarkan data yang diperoleh dari 256 pasien poliklinik endodonsi RSUD Budhi Asih 28 pasien (11\%) memiliki kriteria motivasi menambal gigi buruk, sedangkan 228 pasien (89\%) memiliki kriteria motivasi menambal gigi baik. Kriteria motivasi dinilai dari angka karies gigi yang terawat. Hasil wawancara peneliti dengan responden diperoleh keterangan bahwa pasien mulai sadar akan kesehatan gigi dan mulut setelah mengetahui dukungan program jaminan kesehatan oleh pemerintah berupa BPJS Kesehatan di bidang kesehatan gigi dan mulut.

$$
\text { Motivasi merupakan upaya }
$$

menimbulkan rangsangan, dorongan pada seseorang atau sekelompok masyarakat agar mau berbuat dan bekerjasama untuk melaksanakan sesuatu yang sudah direncanakan untuk mencapai tujuan yang telah ditetapkan. Motivasi akan berhasil dengan sempurna jika tujuan organisasi yang telah ditetapkan juga menjadi tujuan perorangan atau kelompok masyarakat yang akan melaksanakan kegiatan,dan diusahakan agar kegiatan yang diharapkan untuk dilakukan sesuai dengan kemampuan yang dimiliki masyarakat (Lendrawati, 2013).

3. Hubungan Pemahaman Informasi Layanan Jaminan Kesehatan Dengan Motivasi Menambal 
Gigi Pasien Poliklinik Endodonsi RSUD Budhi Asih.

Hasil penelitian menunjukkan bahwa responden yang memiliki pemahaman informasi layanan jaminan kesehatan baik memiliki kriteria motivasi menambal gigi baik tertinggi yaitu $87 \%$. Berdasarkan hasil wawancara hal ini disebabkan oleh pasien telah mendapatkan informasi mengenai kesehatan gigi dan mulut serta pengaruh penting kesehatan gigi dan mulut terhadap kesehatan tubuh secara umum. Informasi sebagai data yang telah diproses, namun pemprosesan tersebut dilakukan untuk suatu tujuan tertentu. Informasi merupakan keterangan, kabar berita, pemberitahuan, penerangan, atau bahan nyata lainnya yang dapat digunakan sebagai bahan kajian analisis untuk mengambil kesimpulan atau keputusan tertentu (Putra, 2020).

Pasien yang memiliki pemahaman informasi layanan jaminan kesehatan sedang memiliki kriteria menambal gigi baik tertinggi $80 \%$, hal ini disebabkan oleh informasi layanan jaminan kesehatan yang telah didapatkan pasien sebelumnya, khususnya layanan jaminan kesehatan dibidang gigi dan mulut. Selain informasi mengenai layanan jaminan kesehatan yang didapatkan pasien juga telah mendapatkan ilmu tentang kesehatan gigi dan mulut dari tenaga kesehatan gigi dan mulut poliklinik RSUD Budhi Asih. Informasi memberikan keterangan atau pengetahuan, sebagai bahan dalam membuat suatu keputusan. Informasi tingkat pengetahuan mengenai hal yang bersangkutan akan bertambah, menurunkan ketidak pastian dengan adanya informasi. Seseorang dapat mengetahui kondisi objektif masalah sehingga dapat mengambil keputusan yang tepat sesuai dengan gambaran kejadian yang diberikan informasi (Setiawan, 2020).

Beberapa tugas dan kewajiban BPJS untuk membayarkan manfaat dan membiayai pelayanan kesehatan sesuai dengan ketentuan program jaminan sosial dan memberikan informasi mengenai penyelenggaraan program jaminan sosial kepada peserta dan masyarakat, memberikan manfaat kepada seluruh peserta sesuai dengan undang-undang tentang sistem jaminan sosial nasional, memberikan informasi kepada peserta mengenai hak dan kewajiban untuk mengikuti ketentuan yang berlaku dan memberikan informasi kepada peserta mengenai prosedur untuk mendapatkan hak dan memenuhi kewajibannya (Kemenkes, 2011). Walmsley (C) Jurusan Keperawatan Gigi Poltekkes Kemenkes Jakarta I J1. Wijaya Kusuma No. 47-48 Cilandak Jakarta Selatan, Indonesia email: jdht@poltekkesjakarta1.ac.id menyatakan bahwa memelihara gigi penting untuk berbagai fungsi seperti untuk makan, berbicara, dan secara sosial mempunyai nilai estetik. Perawatan gigi direncanakan sebaik mungkin untuk mencegah timbulnya masalah gigi dimasa yang akan datang dan membantu memelihara kesehatan gigi (Lendrawati, 2013).

Hasil penelitian menunjukkan bahwa responden yang memiliki informasi layanan jaminan kesehatan kurang memiliki kriteria motivasi menambal gigi baik tertinggi yaitu $92 \%$. Berdasarkan hasil wawancara hal ini disebabkan oleh pasien telah mendapatkan informasi tentang layanan jaminan kesehatan di bidang kesehatan gigi dan mulut, serta pengaruh kesehatan gigi dan mulut terhadap kesehatan tubuh secara umum dan mendapatkan motivasi dari tenaga kesehatan gigi dan mulut yang langsung diberi jadwal perawatan selanjutnya. Informasi diberikan pada seseorang agar dapat mengetahui kondisi objektif masalah, sehingga dapat mengambil keputusan yang tepat sesuai dengan gambaran kejadian yang diberikan melalui informasi tersebut (Setiawan, 2020). Dalam mengabdikan diri petugas kesehatan memberikan informasi-informasi yang berkaitan dengan kebutuhan masyarakat salah satunya jenis layanan kesehatan yang dijamin guna mencapai derajat kesehatan yang optimal (Depkes, 2014).

Badan Penyelenggara Jaminan Sosial (BPJS) Kesehatan berfungsi menyelenggarakan program jaminan kesehatan. Badan Penyelenggara Jaminan Sosial Kesehatan sebagai Badan Pelaksana merupakan badan hukum publik yang dibentuk untuk menyelenggarakan program jaminan kesehatan bagi seluruh rakyat Indonesia. Tujuan diberlakukannya program Jaminan Kesehatan Nasional ini adalah untuk memenuhi kebutuhan kesehatan masyarakat yang layak yang diberikan kepada setiap orang yang telah membayar iuran atau iurannya dibayar oleh Pemerintah (Kemenkes, 2011).

Beberapa pakar mengemukakan bahwa kesehatan rongga mulut merupakan bagian integral dari kesehatan secara umum, namun banyak orang tidak mengetahui bahwa rongga mulut berperan penting bagi kesehatan tubuh (Barahama et al., 2018). Gigi direncanakan sebaik mungkin untuk mencegah timbulnya masalah gigi dimasa yang akan datang dan membantu memelihara kesehatan gigi dengan cara memberikan motivasi untuk menjaga

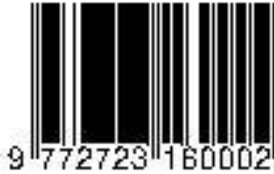


kesehatan gigi secara baik dan benar. Motivasi seseorang untuk menambal giginya merupakan suatu upaya mempertahankan gigi tetap yang digambarkan dalam nilai Performed Treatment Index (PTI) (Lendrawati, 2013). Diharapkan bagi pasien untuk menjaga kesehatan gigi dan mulut, sehingga dapat meminimalkan terjadinya masalah gigi dan mulutnya serta pasien yang masih memiliki karies gigi diharapkan untuk dilakukan penambalan supaya pengunyahan tetap baik dan optimal (Ramdiani, Yulita, Sasongko, \& Purnama, 2020).

\section{Kesimpulan}

Pasien memiliki pemahaman informasi layanan jaminan kesehatan pada kriteria kurang, serta motivasi menambal gigi pada kriteria baik. Hubungan antara informasi layanan jaminan kesehatan dengan motivasi menambal gigi pasien di poliklinik endodonsi RSUD Budhi Asih memiliki kriteria koefisien korelasi sangat rendah. Dalam hal ini pasien yang memiliki informasi layanan jaminan kesehatan yang kurang memiliki motivasi menambal gigi yang baik setelah mendapatkan informasi dari tenaga kesehatan.

\section{Saran}

Saran yang dapat diberikan kepada pasien poliklinik endodonsi RSUD Budhi Asih agar tetap meningkatkan upaya untuk menambal gigi dengan mencari informasi tentang kesehatan gigi dan rutin kontrol ke pelayanan kesehatan gigi dan mulut yang diberikan secara berkesinambungan oleh tenaga kesehatan dari fasilitas kesehatan.

\section{Daftar Pustaka}

Astuti, A. P., Nurmalita, A., \& Doni, rohma F. (2014). Astuti, A. P., \& Rps, A. Nu. (2014). Teknologi Komunikasi dan Perilaku Remaja. Jurnal Analisa Sosiologi. Jurnal Analisa Sosiologi, 3(1), 91-111.

Barahama, F., Masi, G., \& Hutauruk, M. (2018). Hubungan perawatan kebersihan gigi dan mulut dengan kejadian karies gigi pada anak di SD Gmist Smirna Kawio Kecamatan Kepulauan Marore Kabupaten Sangihe. Jurnal Keperawatan, 6(2).

Depkes. (2013). Peraturan Menteri Tentang Pelayanan Kesehatan Pada Jaminan Kesehatan Nasional. Retrieved from Peraturan Menteri Kesehatan Republik Indonesia Nomor 71 Tahun 2013 Tentang Pelayanan Kesehatan Pada Jaminan Kesehatan Nasional website: http://www.jkn.kemkes.go.id/attachment/unduh an/PMK No. 71 Th 2013 ttg Pelayanan Kesehatan Pada JKN.pdf

Depkes. (2014). Undang-Undang Tentang Tenaga Kesehatan. Retrieved from Undang-Undang Republik Indonesia Nomor 36 Tahun 2014 Tentang Tenaga Kesehatan website: http://gajiroum.kemkes.go.id/data/UU_NO_36_ 2014.pdf

Kemenkes. (2009). Undang-Undang Tentang Kesehatan. Retrieved from Undang-Undang Republik Indonesia Nomor 36 Tahun 2009 Tentang Kesehatan website: https://infeksiemerging.kemkes.go.id/download /UU_36_2009_Kesehatan.pdf

Kemenkes. (2011). Undang-Undang Tentang Badan Penyelenggara Jaminan Sosial. Retrieved from Undang-Undang Republik Indonesia Nomor 24 Tahun 2011 Tentang Badan Penyelenggara Jaminan Sosial website: https://bpjskesehatan.go.id/bpjs/dmdocuments/20e674930 84e6d2e600888b1dd9f94f4.pdf

Lendrawati, L. (2013). Motivasi Masyarakat Dalam Memelihara dan Mempertahankan Gigi. Andalas Dental Journal, 1(1), 90-101.

Pangestu, A. H. (2018). Hubungan Pengetahuan Tentang BPJS Kesehatan Gigi dan Mulut dengan Pemanfaatan Fasilitas BPJS Kesehatan Gigi dan Mulut Pada Peserta BPJS di Dusun Watu Ulo Jember. Jurnal Kesehatan.

Putra. (2020). Fungsi, Konsep Dasar\& Jenis Jenis Informasi. Retrieved from https://salamandian.com/pengertian-informasi.

Ramdiani, D., Yulita, I., Sasongko, B. G., \& Purnama, T. (2020). Required Treatment Index (RTI) Pada Pasien Dewasa di Klinik Dokter Gigi Tjang Riyanto Cahyadi Kota Bogor. JDHT Journal of Dental Hygiene and Therapy, $1(2), 55-60$.

Rizqi, H. B. (2016). Pengaruh Motivasi Intrinsik Dan Motivasi Ekstrinsik Terhadap Kinerja Melalui Perilaku Kerja Karyawan Honorer Hotel Dan Pemandian Kebonagung Jember. Jurnal Manajemen.

Setiawan. (2020). Pengertian Informasi, Guru Pendidikan. Retrieved from https://www.gurupendidikan.co.id/pengertianinformasi/.

SIMRS. (2020). Daftar Pasien Masuk Poliklinik Endodonsi Poliklinik Rawat Jalan. 